a more definite conviction that the soul is essentially and ultimately capable of transcending the limitations of the material order. For all its scientific aspects, the author's theory depends ultimately on metaphysical, philosophical presuppositions and it applies the principles of these presuppositions at every stage of advance in the argument.

With much of the negative reasoning and particularly with much of the exegesis of Scripture the reviewer is not in accord; but the frankness and clarity of statement leave the reader at every point able at once to discern the writer's thought and to apprehend its confusion. This confusion is found especially in failure to distinguish substantive and adjective ideas in the no. tions of energy and matter. The work is one of fascinating interest and fertile suggestion.

W. O. Carver.

The Homing Instinct. By Fred Clare Baldwin. 1913. New York. Eaton \& Mains; Cincinnati, Jennings \& Graham. 67 pages. 50c net.

There are many who raise little question about the rational ground of the hope of immortality. Those who do raise the question find their answer, if at all, along lines differing according to the differing temperaments, cultures and habits of the inquirers. The title to this little book sufficiently indicates the line of its answer. How this "Homing instinct" is supported by the Old and New Testament Scriptures and by spiritual life now experienced are indicated in chapters full of the poetic beauty of splendid rhetoric serving as vehicle for a buoyant and hopeful spirit.

W. O. CARver.

A Man's Religion: Letters to Men. By William Fraser McDowell. 1913. New York, Eaton \& Mains; Cincinnati, Jennings \& Graham. 225 pages. 50c net.

These "Letters to Men" were first published in the Adult Bible Class Monthly. They richly deserve this permanent and connected form. They are rich in life and in expression. They 
deal with vital matters in a way to appeal to the good sense, the manly spirit, the holy need of true men in all walks of life and in all stages of religious experience. I know nothing more to my liking for making the appeal to men to live a worthy life. Beliefs a man needs, ideals he must have, practices are his very self in expression. All these are his life and he needs to live that life in relation to God. This book will help him see God and see his own ideal in Jesus Christ.

W. O. Carver.

\section{IV.-RELIGIONS AND MISSIONS.}

Comparative Religion. By F. B. Jevons, Litt. D., Professor of Phllosophy in the University of Durham. Cambridge: At the University Press; New York: G. P. Putnam's Sons, 1913. vii +154 pages. 40c net.

Nothing is more needed in the whole range of the study of Religion than a reliable and balanced work on Comparative Religion. This volume in "The Cambridge Manuals of Science and Literature" is a movement in that direction and has many merits. It cannot, however, be said to meet the need. It was hampered by the narrow limits of space allowed in this series. Then the author is a philosopher rather than a scientist and the method of logic appears in this work to a considerable measure where we needed the methods of the historian and scientist. This defect appears at its worst in the chapter on Monotheism where inferences and logical implications abound but not in a way to convince.

Sacrifice, Magic, Ancestor-Worship and the Future Life are the topies on which the comparative study chiefly dwells. There are some original, valuable and very fruitful views advanced in connection with Buddhism and Mohammedanism. That sacrifice is a form of community worship and not of the individual; that to name one's God is to confess the existence of other gods, are views that are plausibly set forward but not supported by fact or by fuller results of analysis.

The work is fresh, independent, able but not satisfactory as a presentation of the facts of the religious. The superior place 